\title{
Incidence of Injuries in Female and Male Volleyball Players - Prospective Preliminary Study
}

\author{
Kadın ve Erkek Voleybolcularda Yaralanma Insidansı- Prospektif \\ Ön Çalışma
}

\author{
Mehmet Mesut Çelebi', Adil Aksu \\ ${ }^{1}$ Sports Medicine Department, Faculty of Medicine, Ankara University, Ankara, Turkey \\ ${ }^{2}$ Halkbank Sports Club, Ankara, Turkey
}

M.M. Çelebi

0000-0003-0581-6837

A. Aksu

0000-0002-6006-0342

Geliş Tarihi / Date Received: 12.06.2018

Kabul Tarihi / Date Accepted: 10.08.2018

Yayın Tarihi/Published Online: 26.08.2018

\section{Yazışma Adresi /}

Corresponding Author:

Mehmet Mesut Çelebi

Ankara Üniversitesi Tip

Fakültesi, Spor Hekimliği

Anabilim Dalı, Ankara,

Turkey

E-mail: mcelebi@ankara.edu.tr

(C)2018 Türkiye Spor Hekimleri Derneği. Tüm hakları saklıdır.

\section{ABSTRACT}

Objective: To estimate and compare the overall incidences of volleyball injuries in female and male volleyball players in a season.

Material and Methods: 30 players were included from one male and one female volleyball teams of Turkish super league. All recorded injuries during the season were analyzed. A questionnaire about all the players' demographic data was completed. The injuries those occurred during training sessions or matches were recorded by the team physician and physiotherapist during the whole season. The daily injury and illness report form of the International Olympic Committee was used for injury records.

Results: 125 injuries were recorded. 80 of these injuries occured in female players, wheras 45 were in male players. Overall injury incidence was 6,1 injuries/1000 hours. The total injury incidence was 4,3 injuries/1000 hours in male players, 7,9 injuries/1000 hours in females. The incidence of slow-onset and acute-onset overuse injuries was 4.2 , and the incidence of acute injuries was 1.9. Tendinosis/tendinopathy was the most common with 23 injuries and constituted $18.4 \%$ of all volleyball related injuries. The shoulder including clavicle was the most frequently injured area (15.2\% of the injuries)

Conclusion: Injury prevention programs should address especially the shoulder region and tendon injuries.

Key words: Volleyball, sports injury, incidence

öz

Amaç: Kadın ve erkek voleybol oyuncularında bir sezonda meydana gelen yaralanmaların genel insidansını belirlemek ve birbiriyle karşılaştırmak.

Gereç ve Yöntemler: Çalışmaya Türkiye voleybol süper ligi ekiplerinden birinin kadın ve erkek takımlarındaki 30 oyuncunun bir sezonluk yaralanma kayıtları tutulmuştur. Tüm oyuncuların demografik bilgileri kayıt edilmiştir. Antrenman veya maç sırasında meydana gelen yaralanmalar takım doktoru ve fizyoterapisti tarafından kaydedilmiştir. Yaralanmaların kayıt işleminde Uluslararası Olimpiyat Komitesinin günlük yaralanma ve hastalık raporu formu kullanılmıştır.

Bulgular: Sezon boyunca erkek oyuncularda 45, kadın oyuncularda 80 olmak üzere toplam 125 yaralanma kaydedilmiştir. Yaralanma insidansı erkeklerde 4,3/1000 saat, 
kadınlarda 7,9/1000 saat ve toplamda 6,1/1000 saat olarak saptanmıştır. Yavaş başlangıçlı ve akut başlangıçlı aşırı kullanım yaralanma insidansının 4,2/1000 saat, akut yaralanma insidansının ise 1,9/1000 saat olduğu görülmüştür. Tendinozis/tendinopati en sık görülen yaralanma (23 vaka) olmuştur ve tüm yaralanmaların \%18,4'ünü oluşturmuştur. Omuz ve klavikula bölgesi \%15,2 ile en sık yaralanan bölge olarak kaydedilmiştir.

Sonuç: Yaralanma önleme programlarında özellikle omuz bölgesine ve tendon yaralanmalarına odaklanılmalıdır. Anahtar sözcükler: Voleybol, spor yaralanması, insidans

Available at: http://journalofsportsmedicine.org and http://dx.doi.org/10.5152/tjsm.2018.098

Cite this article as: Celebi MM, Aksu A. Incidence of injuries in female and male volleyball players - Prospective preliminary study. Turk J Sports Med. 2018;53(3):109-15.

\section{GíRis}

Voleybol popüler sporlardan biridir ve dünyada yaklaşık olarak 200 milyon kişi tarafından oynanmaktadır (1). Günümüzde en büyük beş uluslararası spordan biridir ve Uluslararası Voleybol Federasyonu (FIVB), kendisine bağlı 220 ulusal federasyon ile dünyanın en büyük uluslararası spor federasyonudur (2). Voleybol, hem yatay hem de dikey olarak vücudun bir bütün olarak hızlı ve kuvvetli hareketlerini içeren bir spordur ve bu tür hareketlerde yer alan büyük kuvvetler nedeniyle yaralanmaların meydana gelmesi kaçınılmazdır (1). Ayrıca voleybolda hem sıçrama hem de smaç vurma gibi sık tekrar gerektiren hareketler olduğundan, aşırı kullanım yaralanmaları da meydana gelmektedir. Ayak bileği burkulması en sık görülen akut yaralanmadır, genellikle temastan kaynaklanır, yani rakip oyuncunun ayağına veya takım arkadaşının ayağına basarak gerçekleșir $(3,4)$. Özellikle topla temastan dolayı, voleybolda akut parmak burkulmaları görülebilmektedir $(5,6)$. Omuz problemleri tekrarlayan smaçlardan kaynaklanabilir, fazla miktarda sıçrama antrenmanı ise diz problemlerine neden olabilir $(7,8)$.

Mevcut araştırmalarda erkek sporcularda görülen voleybol yaralanmaları hakkında çok sinırlı veriler mevcuttur, erkek ve kadın voleybol sporcuları arasındaki yaralanma oranlarının karşılaştırılması dahil olmak üzere bilgi eksiklikleri vardır (9). Reeser ve arkadaşları (10) 4 yıllık izlem sonucunda yaralanma oranlarını üniversiteli ve liseli kadın voleybolcularda sirasiyla $4,06 / 1000$ saat ve $1,24 / 1000$ saat olarak bulmuşlardır. Baugh ve arkadaşlarının 2 sezon boyunca yapmış oldukları bir çalışmada, erkeklerde ve kadınlarda 83 ve 510 yaralanma rapor edilmiş, bu da 1000 saat başına 4.69 ve 7.07 yaralanma oranlarına denk gelmiştir (9). Norveç ve Hollanda'daki ulusal liglerden elde edilen bir sezonluk iki prospektif kohort çalışmada, maç sırasında görülen yaralanma sıklı̆̆ $3-4 / 1000$ saat ve 1-2/1000 saat olarak bildirilmiștir (1, 11). Kadın ve erkek voleybolcu yaralanmalarını kıyaslayan az sayıda çalışma mevcuttur $(1,12)$. Bildiğimiz kadarıyla Türkiye voleybol liginde erkeklerle kadınların yaralanmalarını kıyaslayan bir çalışma mevcut değildir. $\mathrm{Bu}$ çalışma ile bir sezonda aynı kulüpte oynayan kadın ve erkek voleybolcuların yaralanma riskini tanımlamak ve birbiriyle karşılaştırmak amaçlanmıştır. $\mathrm{Bu}$ pilot çalışma ile kadın ve erkek takımlarındaki yaralanmaların insidansı, antrenman ve maçtaki yaralanma farklılıkları, yaralanma bölgeleri hakkında bilgi elde etmek hedeflenmiştir.

\section{GEREÇ VE YÖNTEMLER}

Bu çalışmada, Türkiye voleybol süper ligindeki iki takımın (bir erkek ve bir kadın takımı) sezon boyunca takım doktoru ve fizyoterapisti tarafından kayit edilen yaralanma ve voleyboldan uzak kalma verileri kullanılmıştır. Her bir takımda 15 sporcu olmak üzere toplam 30 sporcunun kayıtları tutulmuştur. Çalışma, Ankara Üniversitesi Tıp Fakültesi tıbbi etik komitesi tarafından onaylanmıștır.

\section{Yaralanma tanımı ve kaydı}

Yaralanma kayıtları Uluslararası Olimpiyat Komitesi'nin "Daily Report on Injuries and Illnesses" yaralanma kayit formu (13) kullanılarak yapılmıștır. Tüm yaralanmalar spor yaralanmaları konusunda uzman bir hekim ve fizyoterapist tarafından kaydedilmiştir. Ayrıca, her antrenman ve maçın toplam süresi ile her 
bir oyuncunun katılım süresi kaydedlmiştir. Kayit formunda oyuncunun yaralanma yeri, yaralanma tipi, tanısı, yaralanmanın doğrudan nedeni belirtilmiştir. Yıl içerisinde tekrarlayan veya farklı bir bölgede ortaya çıkan yaralanmalar ayrı ayrı kayıt altına alınmıştır.

\section{İstatistiksel Analiz}

Veriler SPSS (SPSS for Windows, V.21.0, SPSS, Chicago, Illinois) kullanılarak analiz edilmiştir. Tanımlayıcı veriler, frekanslar ve oranlar, yaralanma tipi, yer, neden gibi alt gruplar oluşturulmuştur. Yaralanma insidansı 1000 antrenman/maç saatinde görülen yaralanmaların sayısı olarak sunulmuştur. İnsidans hesaplanmasında "Yaralanma insidans formülü" kullanılmıştır (Yaralanma İnsidansı = Yıllık yaralanma sayısı X $10^{4}$ / Sporcu sayısı X Haftalık Spor Saati X 52). Erkek ve kadın sporcular için ayrı ayrı ve tümü birlikte olmak üzere, her 1000 saatlik antrenman ve maç için yaralanma sayısı ve insidansı ile her bir oyuncunun antrenman ve maça katılma süresi hesaplanmıștır.

\section{BULGULAR}

Çalışmamıza katılan voleybolcuların yaş, boy ve kiloları Tablo 1 de gösterilmiştir. Sezon boyunca erkek ve kadınlarda toplam 20.400 saatlik bir maruziyet sonucunda 125 yaralanma meydana gelmiştir. Kadınların erkeklere göre daha fazla yaralandığı (sırasıyla 80, 45) görülmüștür. (Tablo 2). Genel yaralanma insidansı 1000 antrenman/maç saati başına kadınlarda 7,9, erkeklerde 4,3 ve toplamda 6,1 olarak saptanmıştır. Erkek sporculardaki yaralanmaların \%57,8'i maçlarda, \%42,2'si antrenmanda, kadın sporculardaki yaralanmaların ise \%61,2'si maçlarda, \%38,8'i antrenmanda ortaya çıkmıştır.

54 yaralanmada sporcuların 1-42 gün arasında voleyboldan uzak kaldığı, 71 yaralanmada ise antrenman veya maçlara devam edebildikleri gözlenmiştir. Yaralanma sonrası voleyboldan uzak kalma süresi ortalama 1,3 hafta, erkek ve kadınlar için voleyboldan uzak kalma süresi sirasiyla ortalama 1,32 ve 1,2 hafta olarak bulunmuştur.

Yavaş başlangıçlı (YB) (örneğin, supraspinatus tendiniti) ve akut başlangıçlı (AB) (örneğin bursit ve stres kırığı) aşırı kullanım yaralanması 86 vakada 4,2/1000 saat insidans ile, akut yaralanma ise 1,9/1000 saat insidans ile 39 vakada görülmüștür. Yaralanma nedenleri Şekil 1a-b'de verilmiştir. Tekrar yaralanma \%3,2'lik oran ile 2 vakada görülmüștür. Tendinozis/tendinopati toplam 23 vaka ve $\% 18,4$ oran ile en fazla görülen yaralanma olmuştur. Kas yaralanması ve eklem/bağ yaralanması ise sirasiyla $\% 15,2$ ve $\% 13,6$ 'llk oranlar ile 2. ve 3. sıklıkta görülen yaralanmalar olmuştur. Yaralanma tipleri Şekil 2'de gösterilmiştir En fazla yaralanan vücut bölgesi ise omuz bölgesi olmuştur. (Şekil 3)

Tablo 1: Voleybolcuların demografik özellikleri

\begin{tabular}{lllll}
\hline & $\mathbf{n}$ & \multicolumn{1}{l}{ Yaş } & Boy & \multicolumn{1}{l}{ Kilo } \\
\hline Kadın & 15 & $24,8(4,7)$ & $185,5(7,8)$ & $69,9(9,6)$ \\
Erkek & 15 & $27,5(5,1)$ & $198,6(8,2)$ & $91,4(9,4)$ \\
\multicolumn{2}{l}{ Ortalama değerler (Standart Sapma) } & & \\
\hline
\end{tabular}


Tablo 2. Yaralanma sayısı ve yaralanma insidansı

\begin{tabular}{|c|c|c|c|c|c|c|c|c|c|}
\hline & \multicolumn{3}{|c|}{ ANTRENMAN } & \multicolumn{3}{|c|}{ MAÇ } & \multicolumn{3}{|c|}{ TOPLAM } \\
\hline & $\begin{array}{l}\text { Süre } \\
\text { (h) }\end{array}$ & $\begin{array}{l}\text { Yaralanma } \\
\text { (n) }\end{array}$ & $\begin{array}{l}\text { İnsidans } \\
\text { (n/1000 h) }\end{array}$ & Süre (h) & $\begin{array}{l}\text { Yaralanma } \\
\text { (n) }\end{array}$ & $\begin{array}{l}\text { İnsidans } \\
\text { (n/1000 h) }\end{array}$ & $\begin{array}{l}\text { Süre } \\
\text { (h) }\end{array}$ & $\begin{array}{l}\text { Yaralanma } \\
\text { (n) }\end{array}$ & $\begin{array}{l}\text { İnsidans } \\
(\mathrm{n} / 1000 \mathrm{~h})\end{array}$ \\
\hline Kadın & 10,125 & $\begin{array}{l}85 \\
(\% 64)\end{array}$ & 7,9 & 8250 & $\begin{array}{l}31 \\
(\% 38,8)\end{array}$ & 3,7 & 1875 & $\begin{array}{l}49 \\
(\% 61,2)\end{array}$ & 26 \\
\hline Erkek & 10,275 & $\begin{array}{l}40 \\
(\% 36)\end{array}$ & 4,3 & 8175 & $\begin{array}{l}19 \\
(\% 42,2)\end{array}$ & 2,3 & 2100 & $\begin{array}{l}26 \\
(\% 57,8)\end{array}$ & 2,3 \\
\hline TOPLAM & 20,400 & $\begin{array}{l}125 \\
(\% 100)\end{array}$ & 6,1 & 16.425 & $\begin{array}{l}50 \\
(\% 40)\end{array}$ & 3 & 3975 & $\begin{array}{l}75 \\
(\% 60)\end{array}$ & 18,8 \\
\hline
\end{tabular}

h: süre (saat), n: yaralanma sayısı
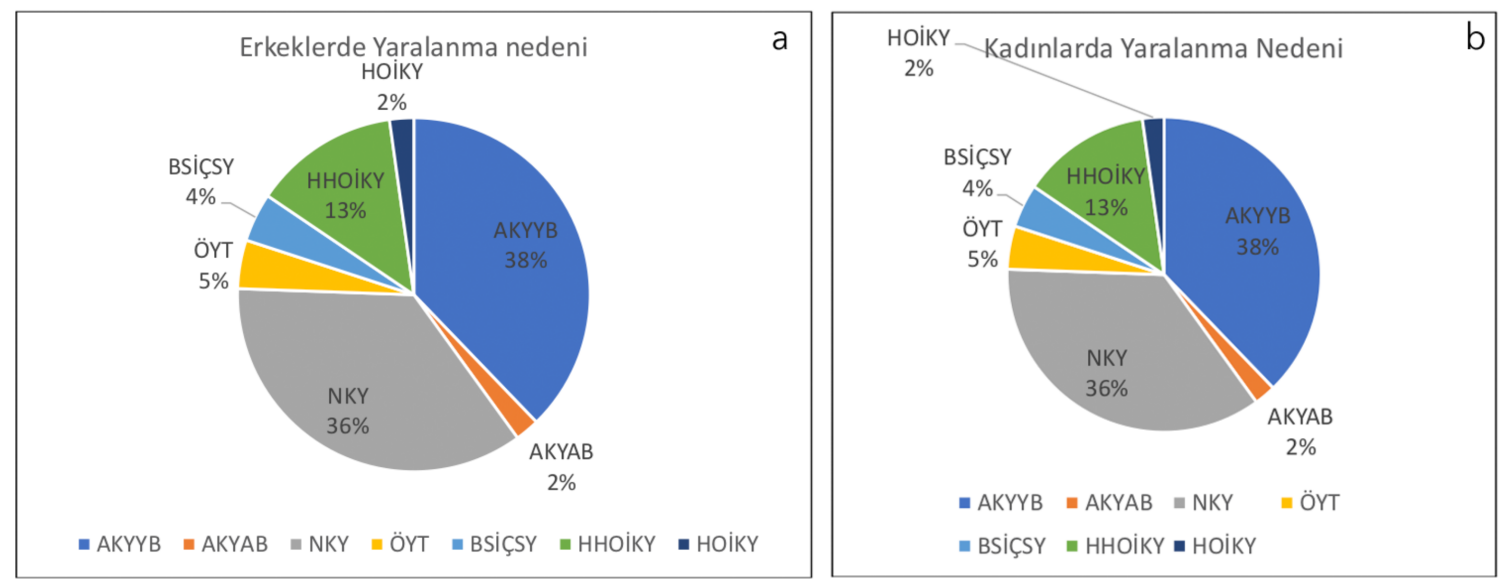

Şekil 1 a-b. Yaralanma nedenleri AKYYB: Așırı kullanım yaralanması yavaș bașlangıçlı, AKYAB: Aşırı kullanım yaralanması akut bașlangıçl, NKY: Non kontakt yaralanma, HHOİ: Hareket halindeki obje ile kontakt yaralanma, HOİKY: Hareket halinde olmayan obje ile kontakt yaralanma, ÖYT: Önceki yaralanmanın tekrarlanması, BSiçSY: Başka sporcu ile çarpışma sonucu yaralanma

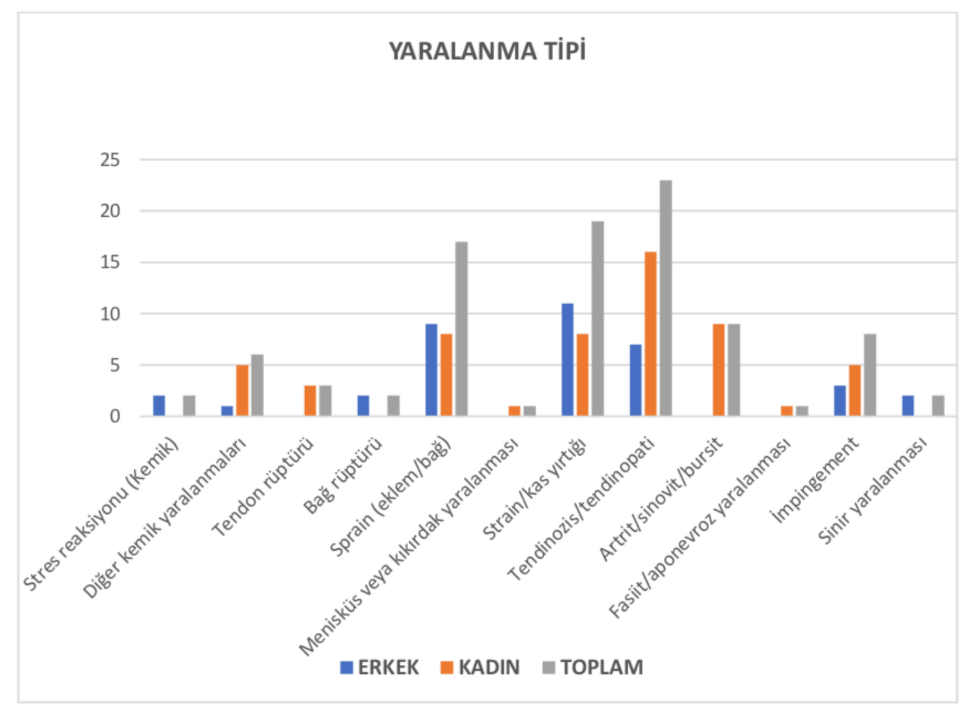

Şekil 2. Yaralanma tipleri 


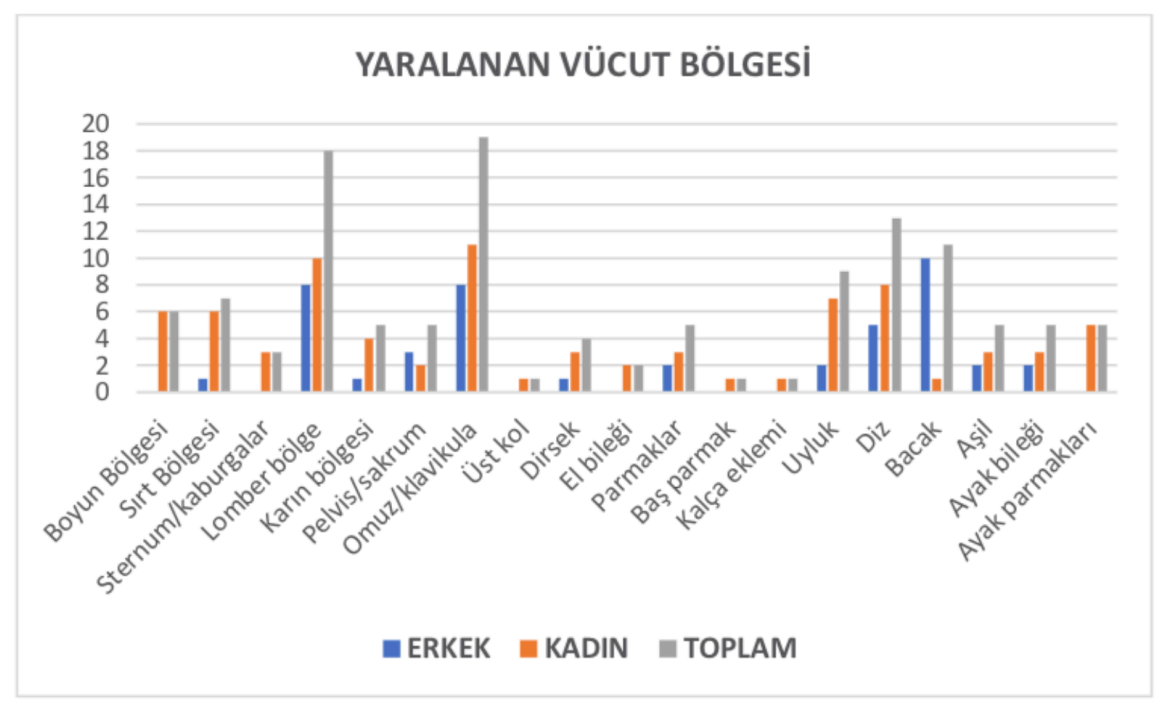

Şekil 3. Yaralanan vücut bölgeleri

\section{TARTIŞMA}

$\mathrm{Bu}$ çalışmanın en önemli gözlemi, omuz bölgesinin en çok yaralanan bölge ve tendinozis/tendinopatinin ise en çok görülen yaralanma tipi olmasıdır. Voleybol temassız bir oyun olduğundan ve rakip oyuncular bir ağ ile ayrıldığından, yaralanma sıklığının düşük olması beklenebilir. Siçrama voleybolda temel hareketlerdendir (14) ve smaç, blok ve servis için çok sayıda sıçrama yapıldı̆̆ından yaralanma oranı düşük değildir. Çalışmamızda yaralanma insidansı 1000 antrenman/maç saati başına kadınlarda 7,9, erkeklerde 4,3 ve toplamda 6,1 olarak bulunmuştur. Aagaard ve arkadaşlarının bir sezonluk retrospektif çalıșmalarında, kadın ve erkek takımlarında 1000 antrenman/maç saatinde toplam yaralanma insidansı 3,8 olarak bildirilmiştir (15). Schafle ve arkadaşları Amerika Birleşik Devlet'lerindeki altı günlük Ulusal Voleybol Turnuvası'ndaki toplam yaralanma insidansını 1000 antrenman/maç saati bașına kadın ve erkeklerde sırasıyla 2.3 ve 1,7 olarak bulmuşlardır (16). Verhagen ve arkadaşlarının (1) çalışmalarında yaralanma insidansı erkeklerde 3, kadınlarda 2,4, Aagaard ve arkadaşlarının çalışmasında (17) ise erkeklerde 4,4, kadınlarda 4,1 ve toplamda 4,3 bulunmuştur.

Çalışmamızda maç ve antrenmanda yaralanma insidansları 1000 antrenman/maç saati başına toplamda 6,1, maç sırasında 18,8 ve antrenmanda 3 olarak bulunmuştur. Bahr ve arkadaşları benzer bir yaralanma tanımı kullandıkları bir sezonluk çalışmalarında, yaralanma insidansını 1000 antrenman/maç saati başına maç sırasında 3,5, antrenmanda 1,5 ve toplamda 1.7 bulmușlardır (11). Verhagen ve arkadaşlarının (1) elde ettikleri sonuçlar bizim çalışmamıza yakın bulunmuştur. Çalışmamızdaki yaralanma insidansının fazla olmasının yaralanma tanımından kaynaklandığı düşünülmektedir. Bizim çalışmamızda voleyboldan uzak kalmaya neden olmayan yaralanmalar da çalışmaya dahil edilmiştir, bu çok da şaşırtıcı değildir, çünkü birçok aşırı kullanım yaralanması oyuncuların antrenmana veya maçlara katılmalarını engellememektedir. Aslında, voleybolda en yaygın görülen yaralanmalardan biri olan sıçrayıcı dizi (patellar tendinopati) tanısı almış çoğu oyuncu antrenman ve maçlarda yer almaya devam etmektedir (11). Çalışma tasarımı, oyuncu sayısının azlığı ve mevcut çalışma ile önceki çalıșmalar arasındaki yaralanma tanımındaki farklılıklar insidans karşılaştırmasını zorlaştırmaktadır.

Voleybolda en sık yaralanan bölgeler ayak bileği yaralanmaları (1, 9-12, 17), üst ekstremite yaralanmaları (16), parmak yaralanmaları (15), diz yaralanmaları $(9,18-20)$ ve omurga yaralanmaları (21) şeklinde bildirilmektedir. Bizim çalışmamızda ise yaralanma sıklı̆̆ 
sırasıyla omuz bölgesi, bel bölgesi ve diz bölgesinde kaydedilmiştir. Ayak bileği yaralanmalarının az sayıda görülmesi bu çalışmanın diğer çalışmalardan en önemli farklılı̆̆ı olarak görülmektedir.

Çalışmamızın en güçlü yanı ise her bir oyuncunun antrenman ve maç katılımına ilișkin bilgilerin günlük olarak takım doktoru ve fizyoterapisti tarafından kayıt edilmiş olmasıdır. Antrenman ve maçların süresine ek olarak, bir oyuncunun antrenman veya maçta bulunup bulunmadığı ve bu yokluğun bir yaralanma nedeniyle olup olmadığı da kaydedilen bilgilerdendir. $\mathrm{Bu}$ nedenle, spor katılımını etkileyen tüm yaralanmaların kayıt edildiği düşünülmektedir. Birçok aşırı kullanım yaralanması ağrı ve rahatsızlık verir, ancak mutlaka oyunun birakılmasina neden olmaz. Ayrıca, akut yaralanmaların da her zaman oyunu bırakmaya neden olmadığını vurgulamakta yarar vardır (1). Bu çalışmada aşırı kullanım yaralanmaları ile birlikte maç/antrenman katılımını etkilemeyen yaralanmalar da dahil edildiğinden yaralanma insidansı daha yüksek bulunmuştur. Çalışmanın en belirgin kısıtlılığı kayıt altına alınmış olan takım ve sporcu sayısının az olmasıdır.

\section{SONUC}

Sonuç olarak, voleybol sporu her ne kadar temassiz bir spor olarak kabul edilse de, yaralanma oranları yüksek olabilmektedir. Öte yandan, yaralanma insidansının diğer çalışmalara göre daha yüksek bulunmuş olmasının kayıt sistemimizden ve bazı așırı kullanım yaralanmalarında sporcuların antrenman ve maçlara devam etmesinden kaynaklandığı düşünülmektedir. Diğer çalışmalarda elde edilen verilerle kıyaslandığında, omuz bölgesinde daha fazla yaralanma saptanmış olması omza yönelik koruyucu çalışmaların yeterince yapılmamış olduğunu düșündürmektedir. Omuz bölgesi yaralanmaları ile tendinopati/tendinozis tanılarının çokluğu koruyucu egzersizlerin önemine bir kez daha vurgu yapılması gerektiğini göstermiştir.

\section{KAYNAKLAR}

1. Verhagen EA, Van der Beek AJ, Bouter LM, et al. A one season prospective cohort study of volleyball injuries. Br J Sports Med. 2004; 38: 477-81.

2. The FIVB. (2018; July 30) http://www.fivb.org/EN/FIVB/FIVB_Structure.asp

3. Verhagen E, van der Beek A, Twisk J, et al. The effect of a proprioceptive balance board training program for the prevention of ankle sprains: a prospective controlled trial. Am J Sports Med. 2004; 32: 1385-93.

4. Bahr $\mathrm{R}$, Karlsen $\mathrm{R}$, Lian $\mathrm{O}$, et al. Incidence and mechanisms of acute ankle inversion injuries in volleyball. Am J Sports Med. 1994; 22: 595-600.

5. Eerkes K. Volleyball injuries. Curr Sports Med Rep. 2012; 11: 251-6.

6. Reeser JC, Verhagen E, Briner WW, et al. Strategies for the prevention of volleyball related injuries. Br J Sports Med. 2006; 40: 594-600; discussion 599-600.

7. Seminati E, Minetti AE. Overuse in volleyball training/practice: A review on shoulder and spinerelated injuries. Eur J Sport Sci. 2013; 13: 732-43.

8. Bahr MA, Bahr R. Jump frequency may contribute to risk of jumper's knee: a study of interindividual and sex differences in a total of 11,943 jumps video recorded during training and matches in young elite volleyball players. Br J Sports Med. 2014; 48: 1322-6.

9. Baugh CM, Weintraub GS, Gregory AJ, et al. Descriptive epidemiology of injuries sustained in National Collegiate Athletic Association men's and women's volleyball, 2013-2014 to 2014-2015. Sports Health. 2018; 10: 60-69.

10. Reeser JC, Gregory A, Berg RL, et al. A Comparison of women's collegiate and girls' high school volleyball injury data collected prospectively over a 4-year period. Sports Health. 2015; 7: 504-10.

11. Bahr R, Bahr IA. Incidence of acute volleyball injuries: a prospective cohort study of injury mechanisms and risk factors. Scand J Med Sci Sports. 1997; 7: 166-71.

12. Bere T, Kruczynski J, Veintimilla N, et al. Injury risk is low among world-class volleyball players: 4-year data from the FIVB Injury Surveillance System. Br J Sports Med. 2015; 49: 1132-7.

13. Daily Report on Injuries and Illnesses. (2012; July 08) https://stillmed.olympic.org/Documents/Commissions PDFfiles/Medical_commission/Daily_report_on_Injurie s_and_Illnesses-London_2012.pdf.

14. Karaca N, Turgay F, Gulcakan GR, et al. Effects of a volleyball match on serum nitric oxide level and oxidant/antioxidant status. Turk J Sports Med. 2018;53:27-36. 
15. Aagaard H, Jorgensen U. Injuries in elite volleyball. Scand J Med Sci Sports. 1996; 6: 228-32.

16. Schafle MD, Requa RK, Patton WL, et al. Injuries in the 1987 National Amateur Volleyball Tournament. Am J Sports Med. 1990; 18: 624-31.

17. Aagaard H, Scavenius $M$, Jorgensen $U$. An epidemiological analysis of the injury pattern in indoor and in beach volleyball. Int J Sports Med. 1997; 18: 21721.

18. Gerberich SG, Luhmann S, Finke C, et al. Analysis of severe injuries associated with volleyball activities. The Physician and Sportsmedicine. 1987; 15: 75-79.
19. Clarsen B, Bahr R, Heymans MW, et al. The prevalence and impact of overuse injuries in five Norwegian sports: Application of a new surveillance method. Scand J Med Sci Sports. 2015; 25: 323-30.

20. Watkins J, Green BN. Volleyball injuries: a survey of injuries of Scottish National League male players. $\mathrm{Br} \mathrm{J}$ Sports Med. 1992; 26: 135-7.

21. Pastor MF, Ezechieli M, Classen L, et al. Prospective study of injury in volleyball players: 6 year results. Technol Health Care. 2015; 23: 637-43. 